\title{
Mucogingival Esthetic Surgery
}

\section{Giovanni Zucchelli}

Publisher: Quitessence Publishing Co Inc

Language: English

ISBN: 978-88-7492-171-3

Edition: $1 / \mathrm{e}$

Publish Year: 2013

Pages: 820, illustrated

Price: US $\$ 390$

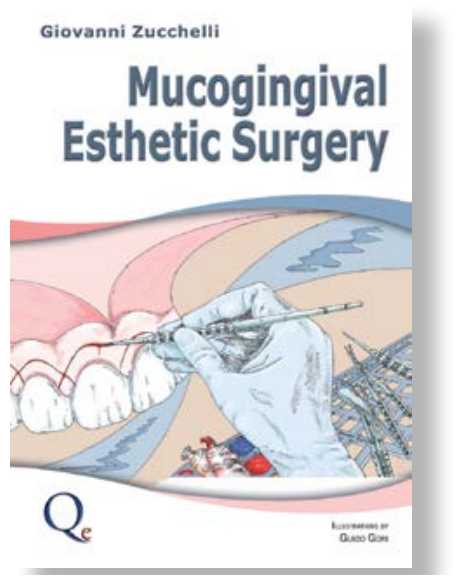

of these two techniques (a two-step technique).

Considerations for connective tissue graft harvesting techniques are described in a separate chapter. The next two chapters are address bilaminar techniques for single and multiple recession defects.

Here are some of the multiple recession defects mentioned in the book: coronally advanced envelope flap, coronally advanced envelope flap and connective tissue graft and restorativeperiodontal treatment.

The last chapters introduce the readers to various clinical cases, the steps that must follow the practitioners, instrumentation required to create predictable results and postsurgical medication recommended for mucogingival surgery.

The book also includes a summary and an explicit atlas of mucogingival surgery techniques which can be easily reviewed.

Practitioners who read this book acquire basic notions on mucogingival surgery required to complete the art and science of modern esthetic surgical techniques. 